\title{
INFRA RED TELEGRAPHY AND TELEPHONY
}

BY

T. W. CASE

During 1916-1917, a search was made for new light reactive materials which would change their electrical resistance on exposure to light. The list of materials examined has been published in the Physical Review. ${ }^{1}$ One of the compounds in this list, lead antimony sulphide, was found to be somewhat active to the infra red. It was also noted that most of the new light reactive compounds found were sulphides. Therefore, further investigation was carried on having to do mainly with compounds containing sulphur. The most promising of these compounds was found to be a thallium sulphide. I This substance showed a light action mainly due to the infra red.

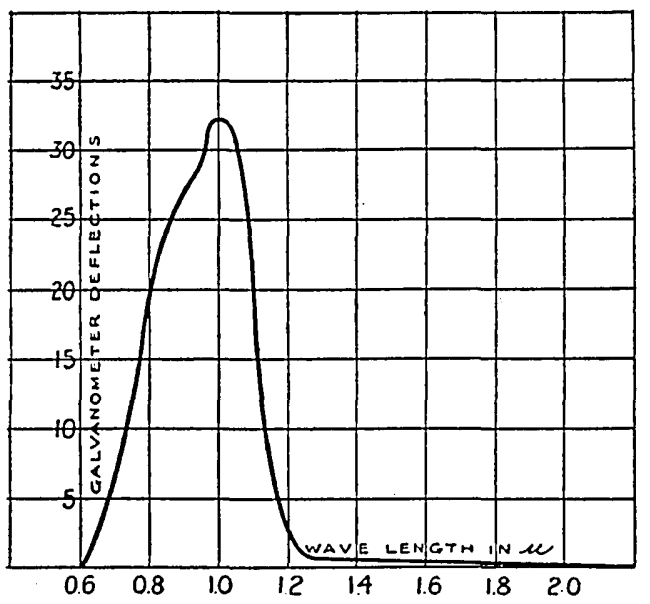

FIG. 1

Fig. 1 shows the spectral action of this thallium sulphide as measured by Dr. W. W. Coblentz. ${ }^{2}$ The sensitivity of the material

${ }^{1}$ Physical Review, Vol. IV, No. 4, April, 1917.

${ }^{2}$ Bureau of Standards paper No. 380. 
was greatly increased by a method of preparation in which the thallium sulphide was slightly oxidized and then placed in a vacuum.

Fig. 2 shows the finished cell which has been termed the "Thalofide Cell." The slightly oxidized thallium sulphide is coated upon a quartz disc, the disc having been previously heated to melt the material which is placed on it. Conducting lines of graphite are drawn over the coated surface and the element mounted in a glass tube, which is then evacuated. ${ }^{3}$.

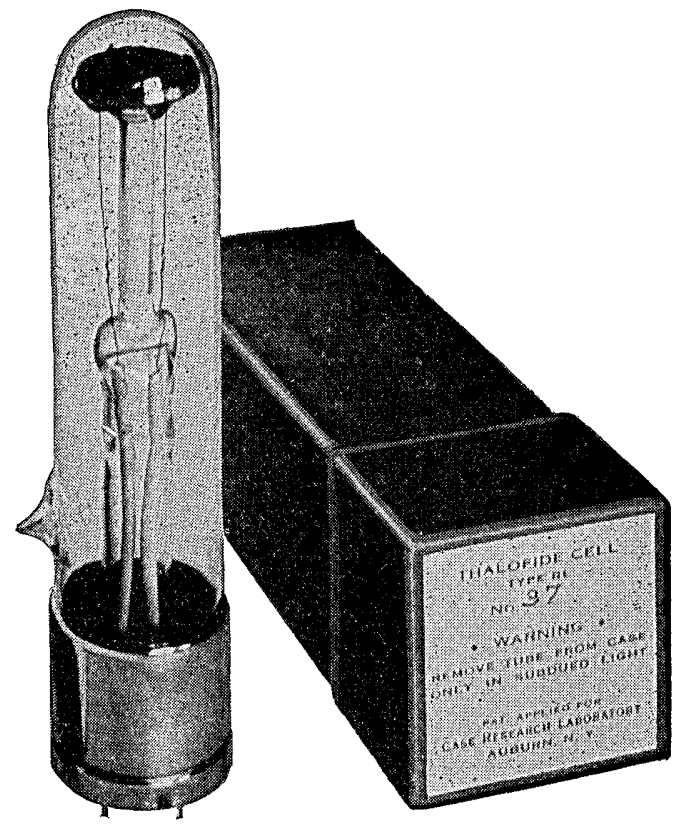

FIG. 2

The action of this cell is in a great many respects similar to the well known selenium cell except for the fact that its action is mainly due to the longer rays as shown in the spectral curve. It also differs in that the induction and deduction periods are more rapid than those of selenium. The resistance of the cells, (5 to 500 megohms) is very much higher than that of the ordinary selenium cell. This latter condition was sought because of the

${ }^{3}$ U. S. Patent number 1316350. 
attendant high (per cent) sensitivity attained between light and dark exposure. This makes the cells ideal for work in conjunction with audion bulbs where low resistance cells are at a disadvantage.

As this cell was developed with the idea of using it for infra red signaling, it was necessary to find an efficient light filter which would transmit the infra red, but not the visible rays. It was found that when Wratten filters, numbers 91,45 , and 53, were superposed, no visible light was transmitted and a high percentage of the infra red came through. This datum was sent to Dr. C. E. K. Mees of the Eastman Kodak Company's Research Laboratory with a request that he combine these three filters into one, which he was successful in doing. The gelatin film was coated on optical plate glass, and the film protected by a suitable cover glass. Ordinary plate glass or window glass, which shows a green color at the edge, was found unsuitable for the transmission of the infra red around 1 micron. The whole filter unit was sealed at the edges to prevent moisture from attacking the gelatin. The transmission of the infra red filter as finally developed is shown in Fig. 3. This curve was plotted by Dr. W. W. Coblentz.

To have an efficient infra red signaling system, it seemed desirable that the signals detected by the Thalofide cell should be made audible. To accomplish this, an audion arrangement was used. The method of interrupting the light at the sending end at an audible frequency was first tried and found to be impractical. Next, it was decided to interrupt the current through the Thalofide cell at the receiving end by mechanical means, for an audible frequency. Dot and dash signals would then be heard as changes in intensity of the audio frequency through the Thalofide cell. These could then be amplified by an audion bulb. This method was discarded a short time later, when it was found that certain connections with an audion bulb containing gas at a prearranged pressure could be made to produce an oscillating current through the Thalofide cell. In this latter arrangement, when the Thalofide cell changed in resistance, the pitch of the audio frequency current changed. This was found to be a very much more sensitive method of registering small changes of resistance in the Thalofide cell. 
The audion bulbs used were of the Western Electric V type. To make these bulbs sensitive for use they were connected to a vacuum system, and baked, and exhausted to a very high vaccum.

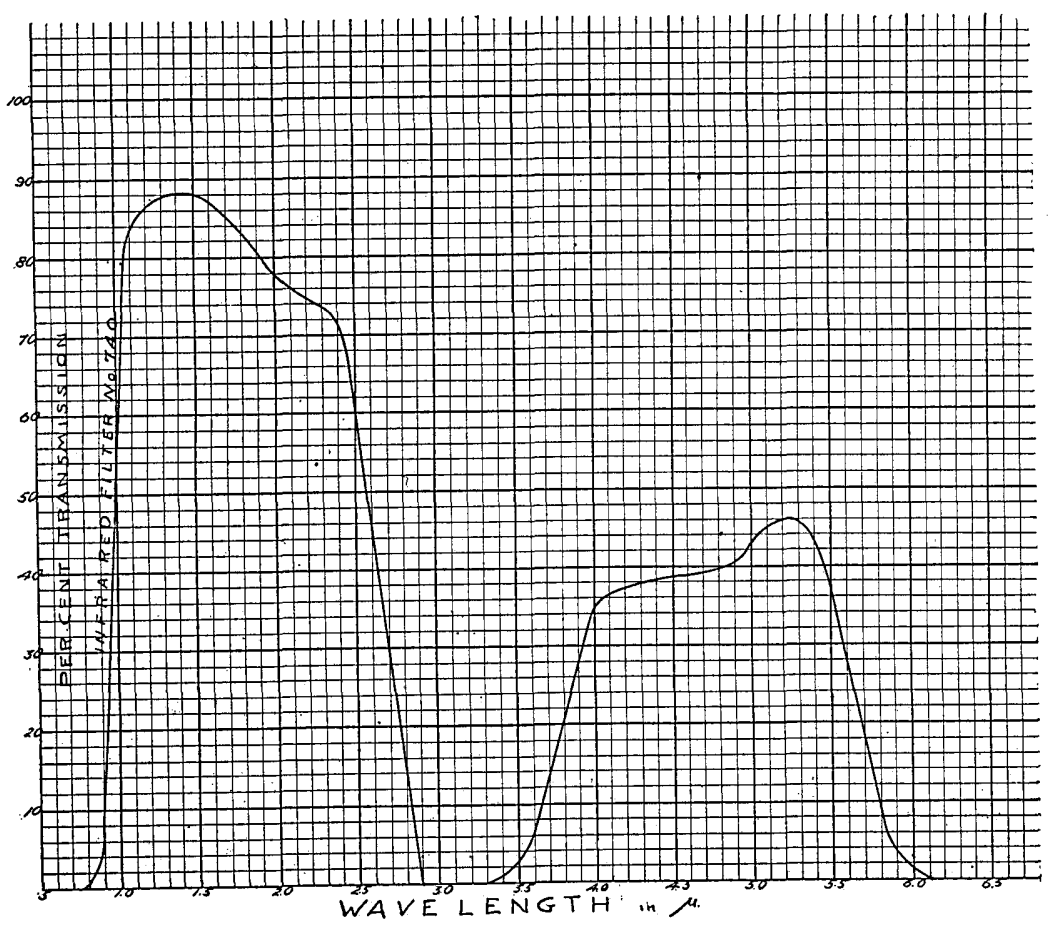

FIG. 3

Argon was then let in and the pressure adjusted until the bulbs oscillated freely at minimum voltage on a test circuit with a predetermined resistance in place of the Thalofide cell. ${ }^{4}$ The wiring used is shown in Fig. 4.

The phone potential is fixed at 120 volts. The cell potential is variable and totals 200 volts. This is to take care of the different dark resistances of the cells. In use, the audion filament is brought to a dull red and the voltage adjusted to give a note of the required pitch in the phones (usually about 1000 cycles) after which the pitch may be changed by slightly adjusting the filament rheostat.

${ }^{4}$ U. S. Patent number 1379166. 


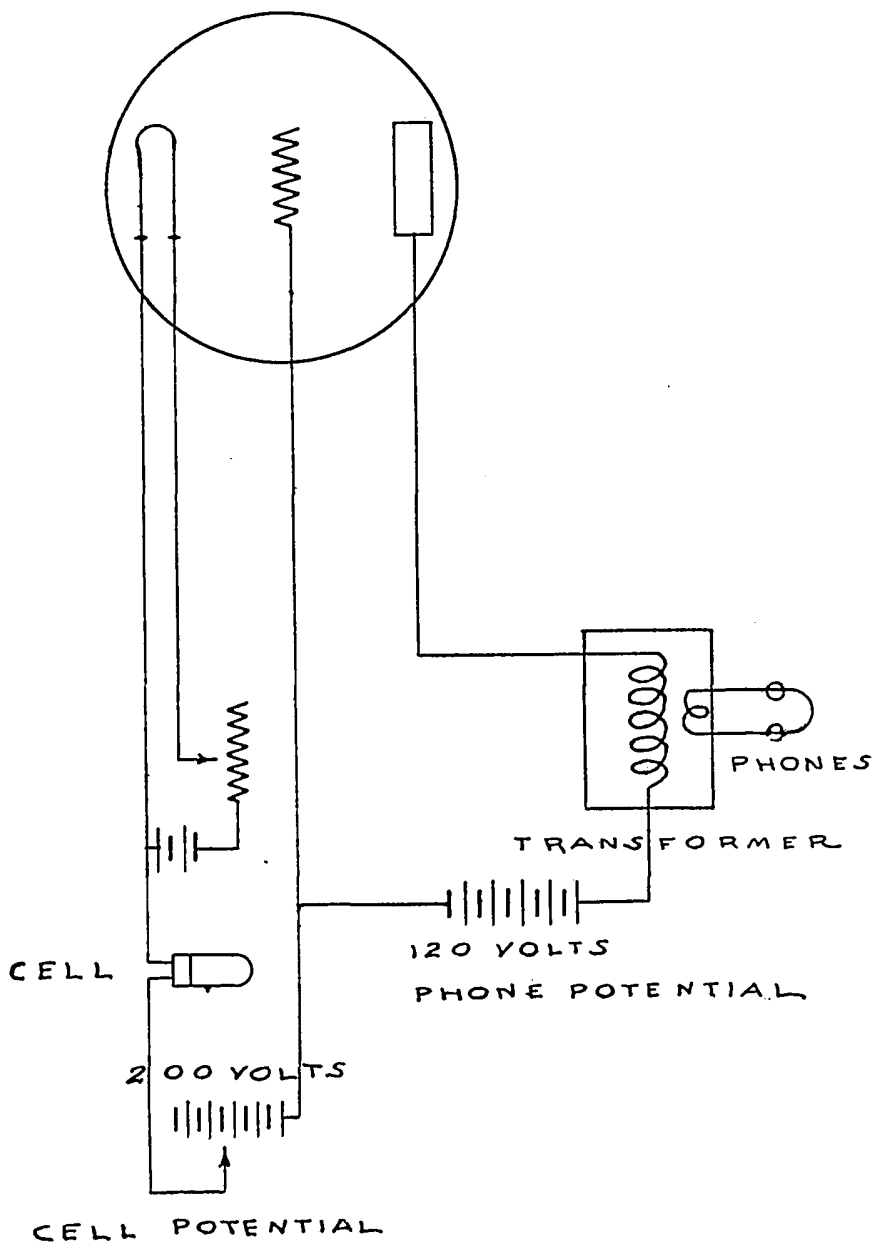

FIG. 4

The action of the Thalofide cell in this circuit may be likened to a valve through which a potential builds up on the plate until a discharge occurs through the gas of the bulb. A fraction of a second is then required until the potential builds up again through the cell. The time rate of building up of consecutive charges and discharges may be changed by increasing or decreasing the filament current with its consequent effect in the ionization of the gas. The sequency of charge and discharge causes the audio 
frequency note heard continually in the phones. When the resistance of the Thalofide cell is lowered by a received signal, the time rate of charge and discharge is varied which is made evident by a change of pitch of the audio frequency note in the phones.

In actual signal work, the Thalofide cell is placed at the focus of a parabolic mirror which serves as a collector of the infra red beam. For a projector of the beam any suitable search light may be used which is properly screened with an infra red filter. A light beam is then projected which is invisible to the eye, and which may be detected by the above described receiving apparatus.

Some of the first official tests of this apparatus were made before representatives of the army and navy in October 1917 between Fort Hancock and the Woolworth building, a distance of about eighteen miles. Messages were successfully transmitted. The signals were so loud that they could be heard at some distance from the phones. These results were obtained in spite of the usual smoky atmospheric conditions between these two points.

The sending apparatus consisted of a Sperry 60 inch search light situated at Fort Hancock and screened by an infra red filter made for this light.

The receiving apparatus consisted of a 24 inch parabolic mirror with the Thalofide cell at its focus. The Thalofide cell was connected to the oscillating circuit described above.

Further tests were made in February, 1918 in conjunction with the coast artillery at Fort Monroe, Va.

At the end of the war, a four mile land set was constructed. This consisted of two eight inch drums, one for sending and one for receiving, rigidly mounted with their axes parallel. The sending projector was mounted at the top. It was made up of an eight inch parabolic reflector with a special eight volt signal lamp placed at the focus. Between the lamp and reflector, a small butterfly shutter was mounted. This could be operated by a key at the side of the apparatus, by means of which the signals could be sent. An infra red filter was placed over the front of the drum. The lower drum was used as the receiver. It contained an eight inch parabolic mirror and a Thalofide cell mounted at the focus of the 
mirror. The Thalofide cell was connected, by means of a flexible lead, to the receiving box which contained the audion circuit. Power was furnished for the lamps and audion by a small storage battery.

The reason that the sending and receiving drum were mounted with parallel axes was to render it easy for two operators to pick each other up in the dark. If one operator sweeps the horizon with his receiving drum and hears a flash signal from the other operator, he leaves his apparatus at the point where he hears the flash signal. He then turns on the invisible beam in the sending drum. His invisible beam will now cover the point from which he received his signal and by sending dots the other operator locates him in like manner.

This portable set can be easily carried and operated by two men and has a range of about four miles.

The atmospheric transmission of the infra red as detected by the Thalofide cell and galvanometer, when compared with the visible as indicated by photometric readings taken with a Sharp-Millar photometer, is shown in the curves, Fig. 5.

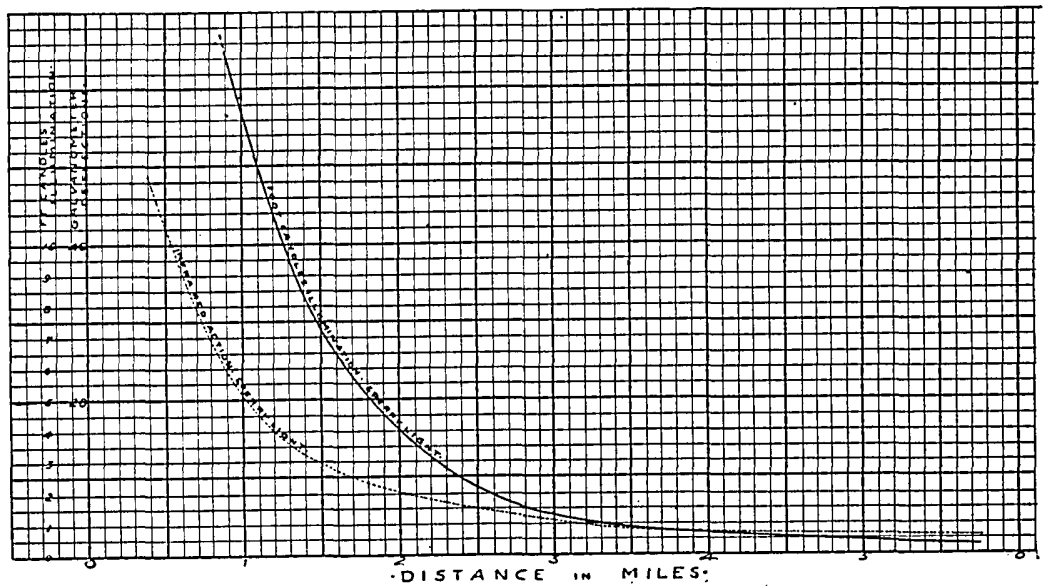

FIG. 5

These curves were taken on a fairly clear night and show that the infra red rays are transmitted through the atmosphere with less absorption than the visible rays. 
During this time, work was also being done to adapt this system for actual telephony with the infra red. The first problem was the development of a suitable and constant high intensity light source, which could be easily varied by sound. The result of this research was a modification of the ordinary manometric flame principle, consisting of a special form of an oxy-acetylene burner in which the oxygen is directed obliquely against opposite sides of an acetylene flame. (See Fig. 6.) This makes a small intense light source, having an area of about .25 square inches and a candle-power of about one hundred and fifty.

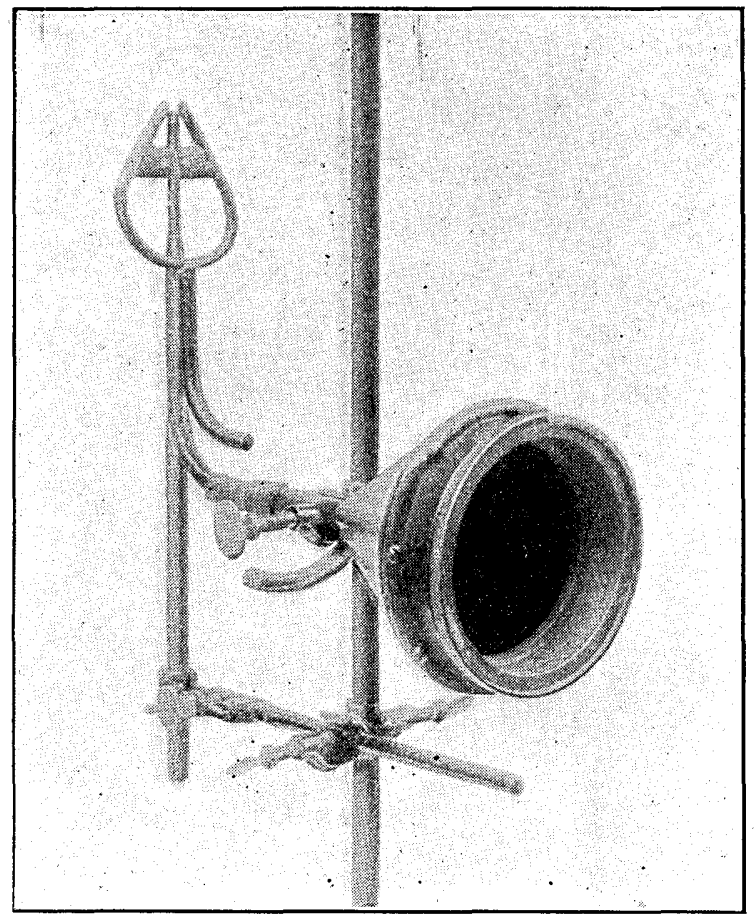

FIG. 6

For the receiving end, the Thalofide cell was connected to a straight audion hook-up for simple and direct amplification. On a clear night, using twenty-four inch sending and receiving projectors, with three step amplification the voice could be easily 
understood at five miles. Similar small sets were made up, consisting of twelve inch projectors and receivers, which gave very good voice tranmission at two miles.

It was realized, at this time, that there would be no demand for such apparatus or its further development except for war purposes, consequently it was decided to stop all further work along this line.

Case Research Laboratory,

AUBURN, N. Y. 